\title{
Radiation induces submandibular gland damage by affecting Cdkn1a expression and regulating expression of miR-486a-3p in a xerostomia mouse model
}

\author{
Wei Wang ${ }^{B-F}$, Caizhi Xiao ${ }^{A, C, E, F}$, Hong Chen ${ }^{B, C, E, F}$, Fangfei $L^{B}, C, F$, Dongqin Xia ${ }^{B, C, E, F}$ \\ Key Laboratory of Biorheological Science and Technology of the Ministry of Education (Chongqing University), Chongqing University Cancer Hospital, China \\ A - research concept and design; $\mathrm{B}$ - collection and/or assembly of data; C - data analysis and interpretation; \\ $D$ - writing the article; $E$ - critical revision of the article; $F$ - final approval of the article
}

Address for correspondence

Caizhi Xiao

E-mail: colorzhaodoc@yeah.net

\section{Funding sources}

Key projects of science and technology of traditional Chinese medicine (grant No. ZY201701001).

Conflict of interest

None declared

Received on February 26, 2021

Reviewed on March 17, 2021

Accepted on May 7, 2021

Published online on September 6, 2021

Cite as

Wang W, Xiao C, Chen H, Li F, Xia D. Radiation induces submandibular gland damage by affecting CdknTa expression and regulating expression of miR-486a-3p in a xerostomia mouse model. Adv Clin Exp Med. 2021;30(9):933-939. doi:10.17219/acem/136457

DOI

10.17219/acem/136457

Copyright

Copyright by Author(s)

This is an article distributed under the terms of the

Creative Commons Attribution 3.0 Unported (CC BY 3.0)

(https://creativecommons.org/licenses/by/3.0/)

\begin{abstract}
Background. Radiotherapy has been proven to be an effective treatment strategy for inhibiting head-andneck cancer. However, side effects are common when using high-dosage irradiation, and the mechanism of action of this therapy has not been fully clarified.

Objectives. To discover targeting molecules involved in an electron radiation-induced xerostomia murine model.

Materials and methods. The xerostomia model mice were divided into Gy-3 $(n=5), G y-7(n=5)$, and $\mathrm{Gy}-21(\mathrm{n}=5)$ groups, and were compared to a negative control (NC) group. Drinking water amount, saliva volume, submandibular gland weight, and body weight were recorded. Real-time polymerase chain reaction (RT-PCR) was performed to amplify gene transcription. Hematoxylin and eosin (H\&E) staining was used to identify submandibular gland damage. The dual-luciferase assay was used to observe the interaction between the Cdkn1a gene and miR-486a-3p.

Results. Electron radiation significantly increased the drinking water amount, and decreased saliva volume and body weight compared to mice without radiation treatment $(p<0.05)$. The H\&E staining showed that electron radiation damaged the submandibular gland. Electron radiation also triggered significantly higher transcription of the C $d k n$ Ta gene in the submandibular gland of xerostomia mice compared to those without radiation treatment $(p<0.05)$. The dual-luciferase assay demonstrated that miR-486a-3p interacted with the (dknta gene (miRNA-mRNA).

Conclusions. Radiation was found to induce damage of the submandibular gland and affect C $d k n 1 a$ expression by regulating the expression of miR-486a-3p in a xerostomia murine model. Therefore, modulation of miR-486a-3p and the Cdkn1a gene in a xerostomia murine model might improve damage of the submandibular gland.
\end{abstract}

Key words: xerostomia, electron radiation, miRNA-mRNA targeting interaction, miR-486a-3p, Cdkn1a 


\section{Background}

Annually worldwide, about 500,000 patients are diagnosed with head-and-neck malignancies, and this tendency is increasing. ${ }^{1,2}$ Radiotherapy has proven to be an effective strategy for treating head-and-neck cancer. However, side effects are common when using high-dosage irradiation ${ }^{3}$ and include xerostomia (a dry mouth caused by salivary gland damage). Usually, xerostomia influences life quality in patients with head-and-neck malignancy. ${ }^{4}$ However, no effective therapeutic regimens have been discovered for xerostomia until now.

In previous studies, plenty of specific mechanisms focusing on dysfunction of salivary glands in xerostomia animal models have been explored, such as necrosis and apoptosis. ${ }^{5,6}$ To date, many studies have discovered that extracellular microRNAs (miRNAs) are involved in the pathogenic process of head-and-neck malignancy and the associated radiotherapy resistance. ${ }^{7,8}$ Lamich hane et al. reported that circulating miRNAs act as prognostic molecular biomarkers for head-and-neck cancer. ${ }^{9}$ Fadhil et al. also proved that miRNAs could act as potential diagnostic biomarkers for human head-and-neck cancer. ${ }^{10}$ A previous study also reported that miR-486-5p is involved in the process of neurogenesis and neovascularization. ${ }^{11}$ Meanwhile, miR-486-5p is also correlated with pyroptosis or apoptosis, and involved in inflammatory diseases. ${ }^{12}$ Moreover, the Cdkn1a-encoded p21 molecule can interact with a series of molecules involved in many key biological processes. ${ }^{13}$ Thus, we speculated that $C d k n 1 a$ might interact with miR-486-5p.

\section{Objectives}

In this study, we hypothesized that miR-486-5p might participate in the pathogenesis of radiotherapy-induced xerostomia in an animal model. Therefore, this study aimed to discover targeting molecule involved in an electron radiation-induced xerostomia animal model.

\section{Materials and methods}

\section{Animals and cells}

A total of 20 specific-pathogen-free (SPF) C57BL/6J mice (Ensiweier Biotechnology Co. Ltd., Chongqing, China) were fed with ad libitum food and water, and housed in conditions with a light/dark cycle of $12 \mathrm{~h} / 12 \mathrm{~h}$ at $23-25^{\circ} \mathrm{C}$.

The Ethical Committee of Chongqing University Cancer Hospital (China) approved this study (approval No. CZLS2021077-A). All of the experiments were conducted in accordance with the Guidance of Care and Use of Laboratory Animals of the National Institutes of Health (NIH).

\section{Xerostomia model generation and grouping}

The mice were divided into a normal control (NC) group $(\mathrm{n}=5)$ and an X-ray irradiation injury xerostomia model group $(n=15)$. Mice in the xerostomia model group were further subdivided into a 3-day electron radiation group (Gy-3 group, $n=5$ ), a 7-day electron radiation group (Gy-7 group, $\mathrm{n}=5)$ and a 21-day electron radiation group (Gy-21 group, $\mathrm{n}=5$ ). Mice in the irradiation injury xerostomia model groups were weighed, anesthetized and placed on a linear accelerator in a supine position (with energy of $9 \mathrm{mV}$ and dosage of $3 \mathrm{~Gy} / \mathrm{min}$ ). The submandibular gland of mice was irradiated with a single dose of 18 Gy electron radiation. Mice in the $\mathrm{NC}$ group were treated with the same method as the radiation model groups, except for the irradiation.

\section{Measurement of parameters}

The drinking water amount was recorded. Saliva was collected and its volume was recorded. The submandibular gland was isolated from xerostomia mice and weighed. The submandibular gland index was calculated using the following formula (Eq. 1):

$\underset{\text { gland index }[\mathrm{mg} / \mathrm{g}]}{\text { submandibular }}=\frac{\text { submandibular gland mass }[\mathrm{mg}]}{\text { body weight of mice }[\mathrm{g}]}$.

\section{RT-PCR assay}

RNAs were extracted from submandibular gland tissues of xerostomia mice using the MiniBEST Universal RNA Extraction Kit (cat. No. 9767; TaKaRa, Tokyo, Japan) and cDNAs were synthesized with the PrimeScript ${ }^{\mathrm{TM}}$ II $1^{\text {st }}$ Strand cDNA Synthesis Kit (cat. No. 6210A; TaKaRa) following the manufacturer's instructions. Transcription of the $C d k n 1 a$ gene was examined with $\mathrm{AceQ}^{\circledR} \mathrm{qPCR}$ SYBR Green Master Mix (cat. No. Q111-02; Vazyme, Shanghai, China) using the generated polymerase chain reaction (PCR) primers (Table 1). The gene transcriptional products were analyzed using a Tanon-1600 gel-scanning system (Tanon, Beijing, China) depending on the protocol of the scanning equipment. Finally, the relative gene transcriptions were evaluated using the previously described $2^{-\Delta \Delta \mathrm{ct}}$ method. ${ }^{14}$

Table 1. Specific primers for the real-time polymerase chain reaction (RT-PCR) assay

\begin{tabular}{|l|c|}
\multicolumn{1}{|c|}{ Genes } & Sequences $\left(5^{\prime}-3^{\prime}\right)$ \\
\hline GAPDH - forward & CAGAAGGGGCGGAGATGAT \\
\hline GAPDH - reverse & AGGCCGGTGCTGAGTATGTC \\
Cdknla - forward & CCCGTGGACAGTGAGCAGTT \\
\hline$C d k n 1 a-$ reverse & GCAGCAGGGCAGAGGAAGTA \\
\hline
\end{tabular}




\section{Hematoxylin and eosin staining}

Submandibular glands were fixed using $4 \%$ paraformaldehyde, dehydrated in ethanol at different gradients for transparency, embedded in paraffin, cut into 5- $\mu \mathrm{m}$ thick sections, and then stained with hematoxylin and eosin $(\mathrm{H} \& \mathrm{E})$ as described by Zhou et al. ${ }^{15}$

\section{Dual-luciferase reporter assay}

$293 \mathrm{~T}$ cells were cultured in 24-well plates for $24 \mathrm{~h}$ and co-transfected using pmir-Glo-WtCdkn1a+pTK-NC and pmir-Glo-WtCdkn1a+pTK+mmu-miR-486a-3p or pmir-Glo-MuCdkn1a+pTK-NC and pmir-GloMuCdkn1a+pTK+mmu-miR-486a-3p. The transfections were carried out using Lipofectamine ${ }^{\mathrm{TM}} 2000$ (Thermo Fisher Scientific, Waltham, USA) as instructed by the manufacturer. About $48 \mathrm{~h}$ post-transfection, the dual-luciferase reporter assay system (Promega, Madison, USA) was applied to verify firefly luciferase normalized to Renilla luciferase (ratio).

A

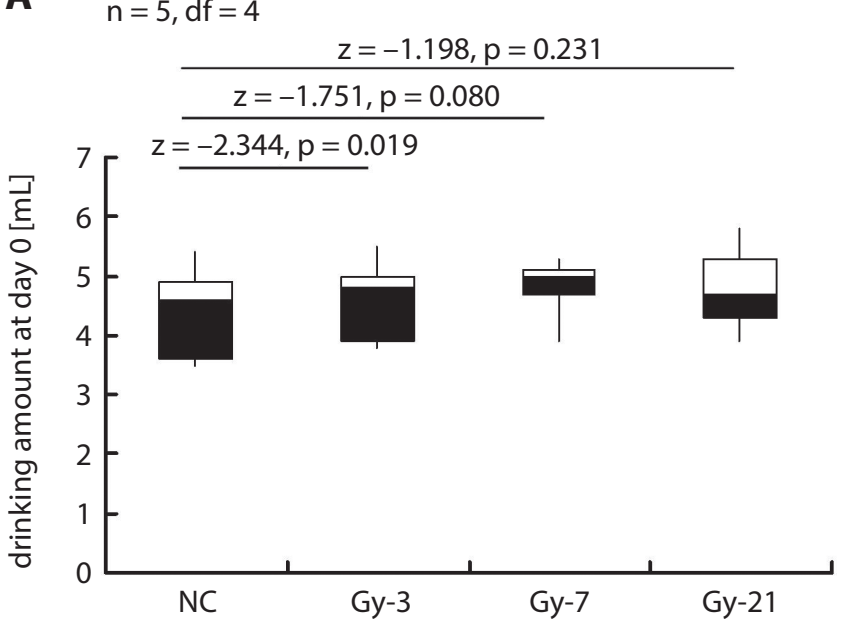

C

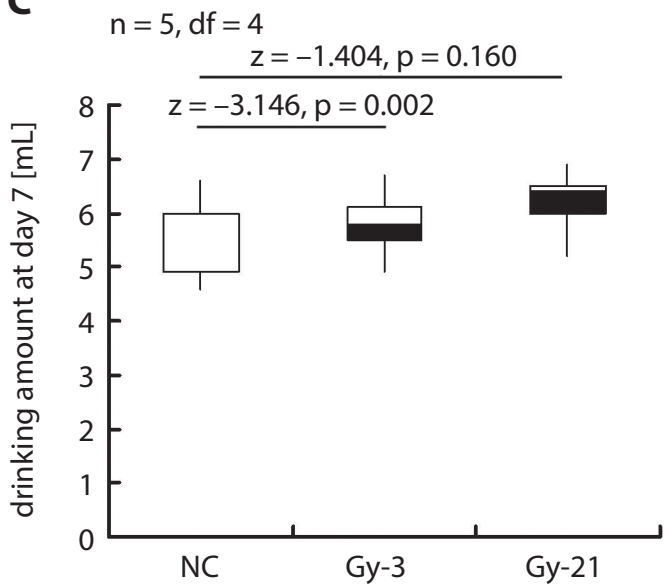

\section{Statistical analyses}

Data are reported as mean \pm standard deviation (SD) and analyzed using IBM SPSS Statistics for Windows v. 19.0 software (IBM Corp., Armonk, USA). The Mann-Whitney U test was used to analyze the differences between 2 groups. A value of $\mathrm{p}<0.05$ was considered to be a statistically significant difference.

\section{Results}

\section{Electron radiation increased the drinking amounts of xerostomia mice}

Electron radiation greatly increased the drinking water amount in xerostomia mice compared to those in the NC group at 0 days (Fig. 1A), 3 days (Fig. 1B), 7 days (Fig. 1C), and 21 days (Fig. 1D) after radiation injury. These results suggest that electron radiation obviously increased the drinking water amount in xerostomia mice.

B

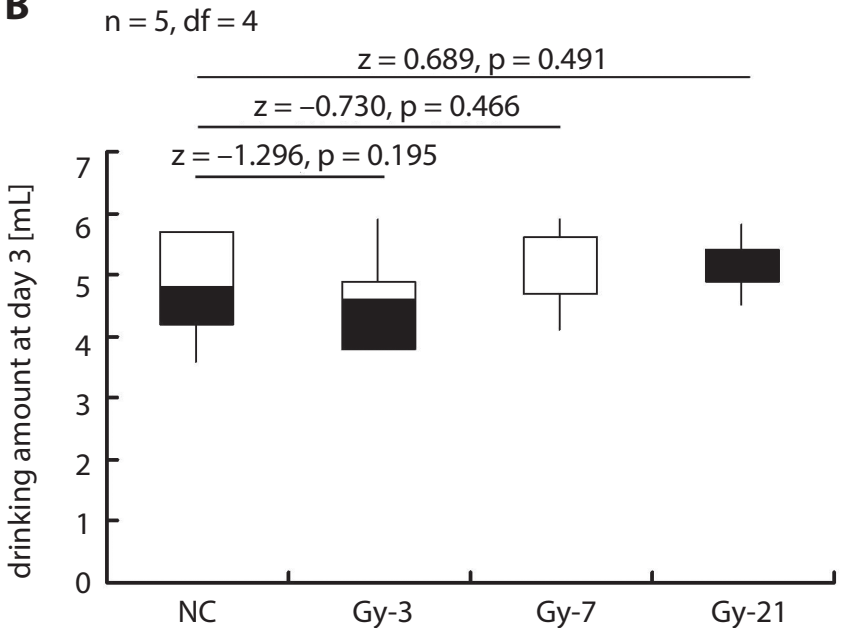

D $n=5, d f=4$

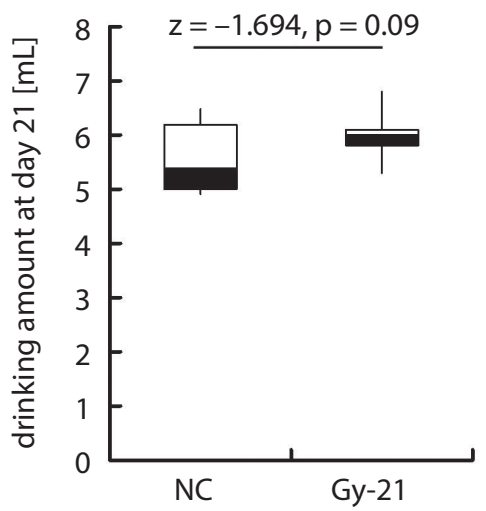

Fig. 1. Effects of electron radiation on drinking water amount (mean \pm SD) 0 days $(A), 3$ days $(B), 7$ days $(C)$, and 21 days (D) after the radiation treatment ( $n=5$ for each group). The white and black bar charts represent the negative control (NC) group and Gy-treated groups, respectively. The $p$-values for comparisons between groups are shown in the images. $\mathrm{df}$ - degrees of freedom 


\section{Electron radiation reduced the body weight of xerostomia mice}

At 3 days (Gy-3 group, Fig. 2A, $\mathrm{p}=0.016), 7$ days (Gy-7 group, Fig. $2 \mathrm{~B}, \mathrm{p}=0.000$ ) and 21 days (Gy-21 group, Fig. $2 \mathrm{C}$, $\mathrm{p}=0.000$ ) after the administration of electron radiation, the body weight of mice was significantly decreased compared to mice in the $\mathrm{NC}$ group. These results suggest that electron radiation reduced the body weight of xerostomia mice.

\section{Electron radiation reduced the submandibular gland weight in xerostomia mice}

The submandibular gland weight of xerostomia mice in the Gy-3, Gy-7 and Gy-21 groups was significantly reduced compared to the submandibular gland weight of mice in the $\mathrm{NC}$ group (Fig. $3 \mathrm{~A}$, all $\mathrm{p}=0.001$ ) in a timedependent manner. In addition, the submandibular gland index of xerostomia mice in the Gy-21 group was markedly decreased compared to the index in the NC group (Fig. 3B, $\mathrm{p}=0.000)$. However, there were no obvious changes in the submandibular gland index in the Gy-3 and Gy-7 groups compared with the $\mathrm{NC}$ group (Fig. 3B, $\mathrm{p}=0.963$ and $\mathrm{p}=0.357$, respectively). Furthermore, the saliva volume of electron radiation-treated mice (Gy-3, Gy-7 and Gy-21 groups) was significantly lower compared to xerostomia mice in the $\mathrm{NC}$ group (Fig. $3 \mathrm{C}$, all $\mathrm{p}=0.001$ ).

\section{Electron radiation damaged the submandibular gland structure in xerostomia mice}

In the NC group, the glands could be seen, the nucleus was close to the base, arranged in an orderly manner, and blood vessels could be seen in the stroma (Fig. 4). In the electron radiation-treated groups, the submandibular gland was atrophied, the number of cells was decreased, the structure of the gland tissue was loose, and the space between glandular lobules was enlarged (Fig. 4).

\section{Electron radiation triggered an increase in Cdkn1a gene transcription}

The results of the bioinformatics and miRNA/mRNA association analysis (Kyoto Encyclopedia of Genes and Genomes (KEGG) information analysis) (http://www. genome.ad.jp/kegg/) showed that the targeting gene,
A

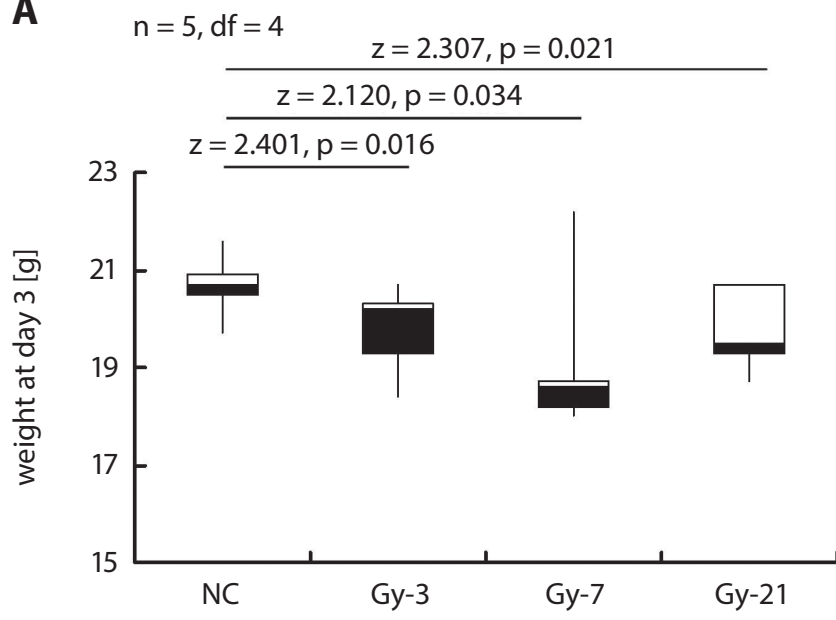

B

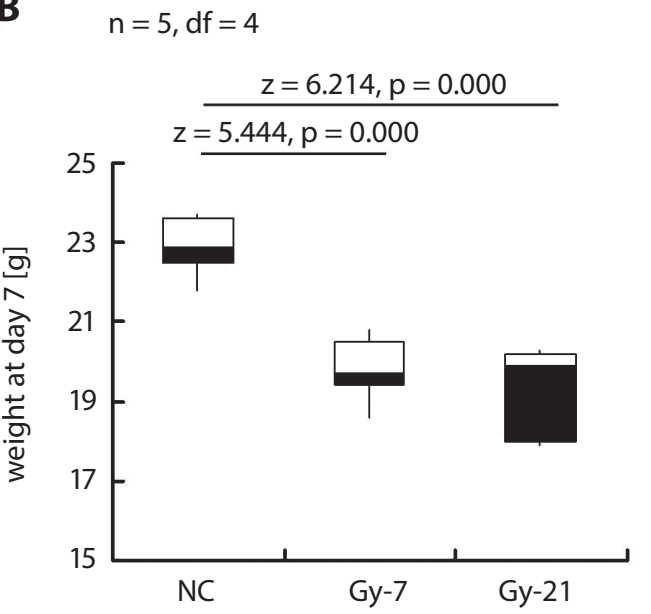

C

$\mathrm{n}=5, \mathrm{df}=4$

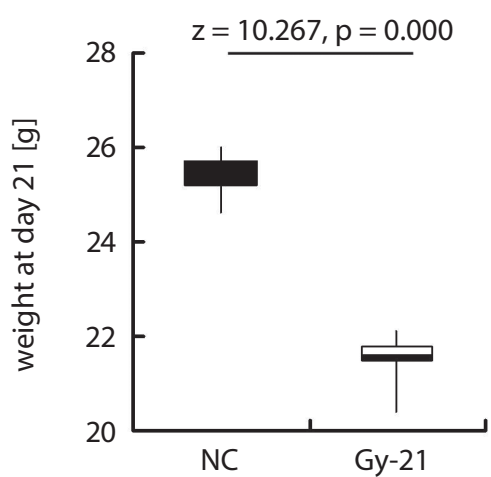

Fig. 2. Electron radiation decreased the body weight (mean \pm SD) of xerostomia mice 3 days (A), 7 days (B) and 21 days (C) after the radiation treatment ( $n=5$ for each group). The white and black bar charts represent the negative control (NC) group and Gy-treated groups, respectively. The $p$-values for comparisons between groups are shown in the images. $\mathrm{df}$ - degrees of freedom 
A

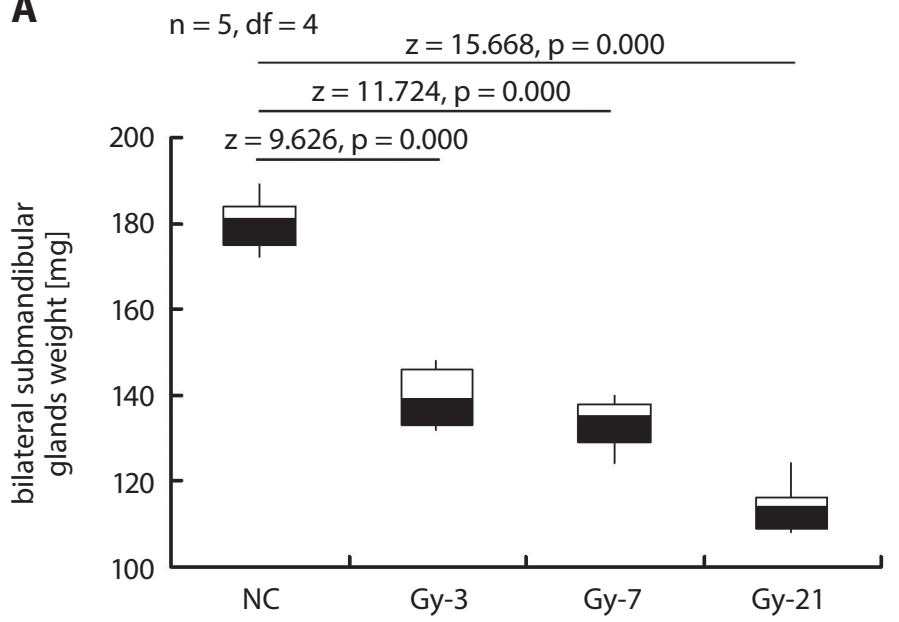

B

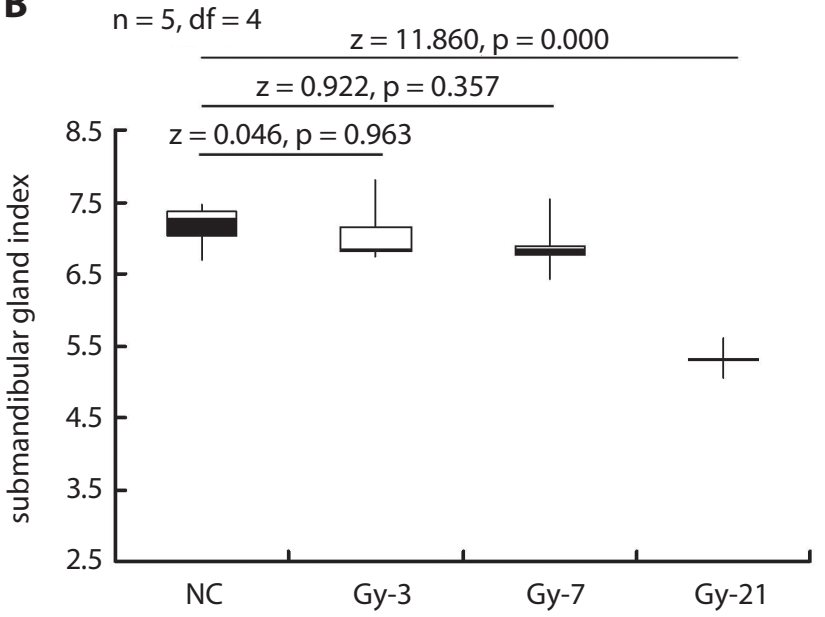

C

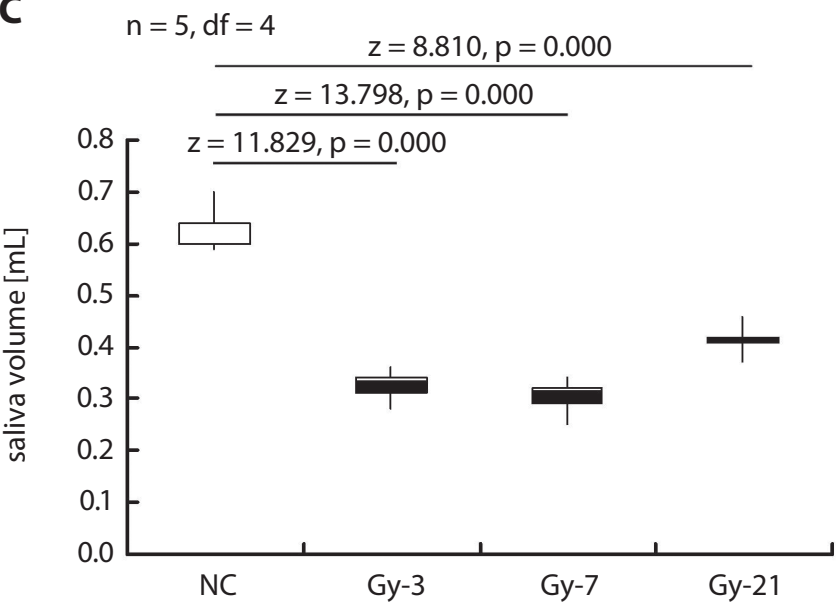

Fig. 3. Effects of electron radiation on the submandibular gland weight (A), submandibular gland index (B), and saliva volume (C) of xerostomia mice $(n=5$ for each group). All data are illustrated as mean \pm SD. The white and black bar charts represent the negative control (NC) group and Gy-treated groups, respectively. The $\mathrm{p}$-values for comparisons between groups are shown in the images. $\mathrm{df}$ - degrees of freedom

NC

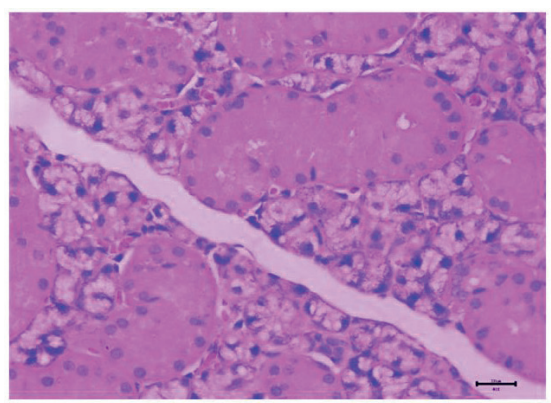

Gy-7

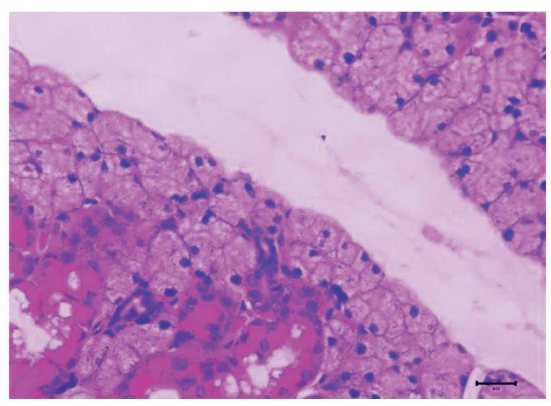

Gy-3

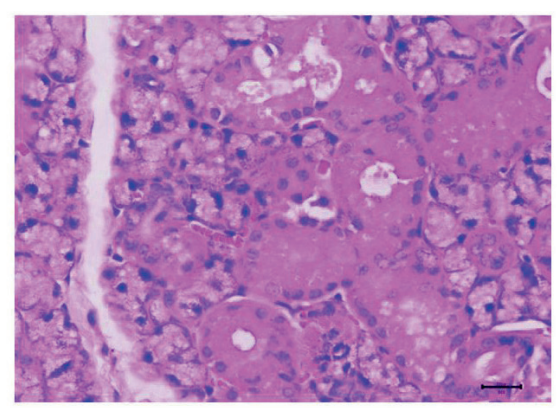

Gy-21

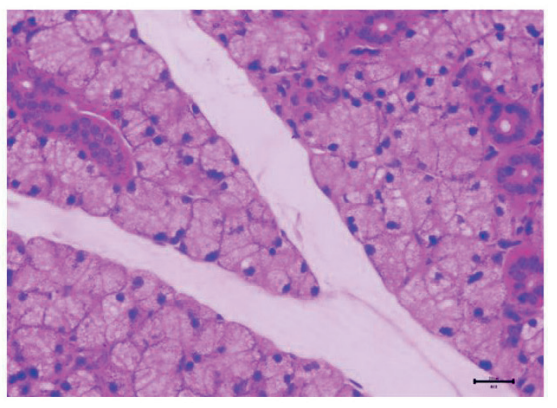

Fig. 4. Electron radiation damaged the structure of the submandibular gland, as determined with hematoxylin and eosin (H\&E) staining ( $n=5$ for each group). NC - negative control 


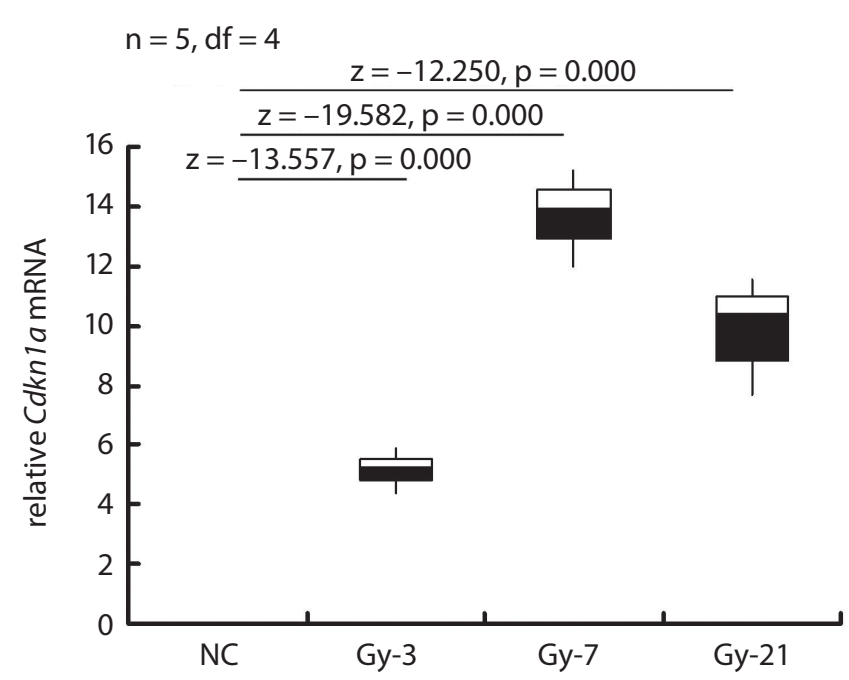

Fig. 5. Electron radiation triggered transcription changes of the Cdknla gene ( $n=5$ for each group). All data are illustrated as mean \pm SD. The white and black bar charts represent the negative control (NC) group and Gy-treated groups, respectively. The $p$-values for comparisons between groups are shown in the images. $\mathrm{df}$ - degrees of freedom

ENSMUSG00000023067 (Cdkn1a), related to xerostomia, was enriched in the p53 signaling pathway. According to the real-time PCR (RT-PCR) findings, Cdkn1a gene transcription was significantly increased in mice in the radiation groups compared to mice in the $\mathrm{NC}$ group 3 days $(\mathrm{p}=0.000), 7$ days $(\mathrm{p}=0.000)$ and 21 days $(\mathrm{p}=0.000)$ after the electron radiation treatment (Fig. 5). Therefore, we speculate that $C d k n 1 a$ might be involved in the pathogenesis of xerostomia.

\section{miR-486a-3p interacted with the Cdkn1a gene}

As can be observed in Fig. 6, mmu-miR-486a-3p regulated expression of luciferase in 3'-UTR of the Cdkn1a gene $(\mathrm{p}=0.001)$. Therefore, $\mathrm{mmu}-\mathrm{miR}-486 \mathrm{a}-3 \mathrm{p}$ effectively regulated the expression of luciferase through binding at 3'-UTR of the Cdkn1a gene.

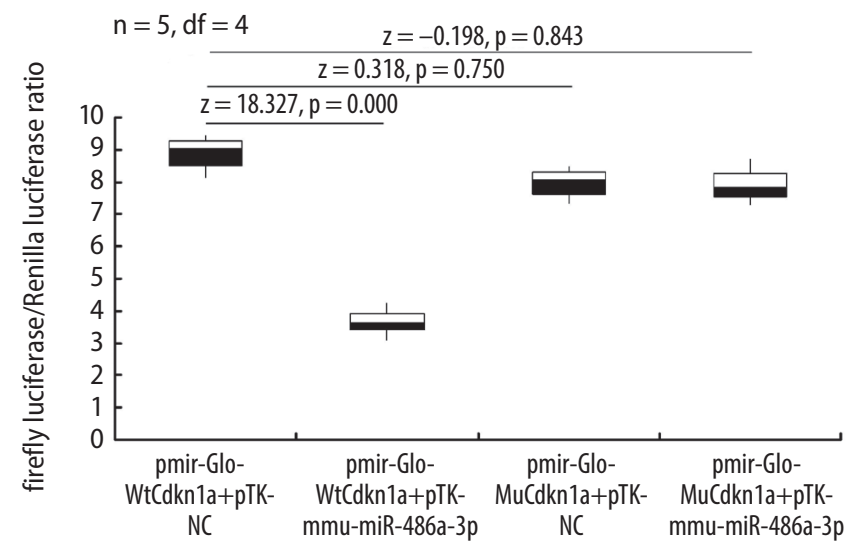

Fig. 6. miR-486a-3p interacted with the Cdknla gene, as shown using the dual-luciferase assay. The $p$-values for comparisons between groups are shown in the images. df - degrees of freedom

\section{Discussion}

Head-and-neck cancer patients usually suffer from radiotherapy-induced dysfunction of the salivary glands. ${ }^{16}$ The submandibular gland secretes about ${ }^{2} / 3$ of the amount of unstimulated saliva. ${ }^{4,17}$ Therefore, this study mainly focused on investigating the functions of the submandibular gland in xerostomia mice. Previous studies have reported that head-and-neck cancer patients undergoing radiotherapy treatment usually demonstrate decreased salivary secretion and damaged submandibular glands. ${ }^{18,19}$ Thus, it is crucial to discover the specific mechanisms for radiation-induced submandibular gland dysfunction and identify the associated molecules.

In this study, we found that electron radiation markedly increased the drinking water amount, decreased saliva volume and body weight, and reduced submandibular gland weight and submandibular gland index of mice compared to those without electron radiation treatment. As shown by these results, the electron radiation-induced symptoms in mice are consistent with those in radiation-treated cancer patients. ${ }^{20}$ Based on the H\&E staining results, it can be stated that electron radiation damaged the structure of the submandibular gland, resulting in an atrophied gland, decreased cell amounts, loose gland tissues, and enlarged spaces between glandular lobules. We believe that electron radiation might induce the death of cells in the submandibular gland tissues of mice.

According to the KEGG bioinformatics analysis, the $C d k n 1 a$ gene is highly expressed in submandibular gland tissues. Therefore, it was selected for the dualluciferase reporter assay to observe the potential interaction with miR-486. As previous studies have documented, plenty of miRNAs have been discovered in the submandibular glands. ${ }^{21,22}$ The miR-486 has been proven to participate in the apoptosis process of cells in different disorders. Luo et al. found that $m i R-486-5 p$ promoted apoptosis in an acute lung injury animal model. ${ }^{23}$ Fan et al. reported that miR-486 reduction could protect cardiomyocytes against cell injury by inducing apoptosis. ${ }^{24}$ The miRNA/mRNA association analysis identified that, taking $C d k n 1 a$ as the targeting gene, miR-486 demonstrated the most remarkable change. Therefore, we analyzed the relationship between $C d k n 1 a$ and $m i R-486 a-3 p$ and found that $m i R-486 a-3 p$ interacts with $C d k n 1 a$, which is a typical miRNA-mRNA targeting interaction. ${ }^{25}$

\section{Limitations}

Firstly, this study only clarified the interaction between $m i R-486 a-3 p$ and $C d k n 1 a$ in a xerostomia murine model. The downstream molecules involved in the pathological process have not been determined. Secondly, there might be other miRNAs or miRNA-mRNA targeting interactions that participate in the xerostomia process, 
which need to be investigated in future studies. Thirdly, this study mainly clarified the miRNA-mRNA targeting interaction between $m i R-486 a-3 p$ and the $C d k n 1 a$ gene. However, the endogenous expression of $m i R-486 a-3 p$ and the effects of radiation on $m i R-486 a-3 p$ expression have not been determined. Fourthly, this study is only a preliminary investigation of the effects of radiation on xerostomia and proved that $m i R-486 a-3 p$ is involved in the effects of radiation. However, whether a deficiency of $m i R-486 a-$ $3 p$ could affect $C d k n 1 a$ expression has not been determined. Lastly, the sample size of this study is small ( $\mathrm{n}=5$ for each group). Therefore, in a follow-up study, we plan to further clarify the specific mechanism for radiationcaused xerostomia in animal models.

\section{Conclusions}

Radiation induces damage of the submandibular gland and affects $C d k n 1 a$ expression by regulating the expression of $m i R-486 a-3 p$ in a xerostomia mouse model. Therefore, modulating $m i R-486 a-3 p$ and the $C d k n 1 a$ gene in a xerostomia murine model might reverse damage of the submandibular gland.

\section{ORCID iDs}

Wei Wang (1) https://orcid.org/0000-0002-1669-9747 Caizhi Xiao (1) https://orcid.org/0000-0003-0503-7964 Hong Chen (1) https://orcid.org/0000-0003-1403-7157 Fangfei Li (1) https://orcid.org/0000-0003-2710-7089 Dongqin Xia (1) https://orcid.org/0000-0001-6677-1105

\section{References}

1. Adesanya MR, Redman RS, Baum BJ, O'Connell BC. Immediate inflammatory responses to adenovirus-mediated gene transfer in rat salivary glands. Hum Gene Ther. 1996;7(9):1085-1093. doi:10.1089/hum. 1996.7.9-1085

2. Baum BJ, Zheng C, Cotrim AP, et al. Aquaporin-1 gene transfer to correct radiation-induced salivary hypofunction. Handb Exp Pharmacol. 2009;190:403-418. doi:10.1007/978-3-540-79885-9_20

3. Emami B, Lyman J, Brown A, et al. Tolerance of normal tissue to therapeutic irradiation. Int J Radiat Oncol Biol Phys. 1991;21(1):109-122. doi:10.1016/0360-3016(91)90171-y

4. Limesand KH, Said S, Anderson SM. Suppression of radiation-induced salivary gland dysfunction by IGF-1. PLoS One. 2009;4(3):e4663. doi:10.1371/journal.pone.0004663

5. Pucar D, Groves MW, Biddinger P, Figueroa R, Williams HT. Head and neck cancer soft tissue radiation necrosis: Diagnostic challenge. Clin NuclMed. 2019;44(2):e110-e112. doi:10.1097/RLU.0000000000002356

6. Paardekooper GM, Cammelli S, Zeilstra LJ, Coppes RP, Konings AW. Radiation-induced apoptosis in relation to acute impairment of rat salivary gland function. Int J Radiat Biol. 1998;73(6):641-648. doi:10. 1080/095530098141898

7. Nowicka Z, Stawiski K, Tomasik B, Fendler W. Extracellular miRNAs as biomarkers of head and neck cancer progression and metastasis. Int J Mol Sci. 2019;20(19):4799. doi:10.3390/ijms20194799

8. Jing X, Gao Z, Tian L, Liu M. Expressions of miR-122a and miR-3195 in laryngeal cancer and their effects on the proliferation and apoptosis of laryngeal cancer cell Hep-2. Adv Clin Exp Med. 2020;29(5): 525-534. doi:10.17219/acem/118848
9. Lamichhane SR, Thachil T, Gee H, Milic N. Circulating microRNAs as prognostic molecular biomarkers in human head and neck cancer: A systematic review and meta-analysis. Dis Markers. 2019;2019: 8632018. doi:10.1155/2019/8632018

10. Fadhil RS, Wei MQ, Nikolarakos D, Good D, Nair RG. Salivary microRNA miR-let-7a-5p and miR-3928 could be used as potential diagnostic bio-markers for head and meck squamous cell carcinoma. PLoS One. 2020;15(3):e0221779. doi:10.1371/journal.pone.0221779

11. Dori $M$, Cavalli $D$, Lesche $M$, et al. MicroRNA profiling of mouse cortical prognostors and neurons reveals miR-486-5p as a regulator of neurogenesis. Development. 2020;147(9):dev190520. doi:10.1242/ dev.190520

12. Zhang C, Gong Y, Li N, et al. Long non-coding RNA Kcnq1to1 promotes cC5b-9-induced podocyte pyroptosis by inhibiting miR-486-3p and upregulating NLRP3. Am J Physiol Cell Physiol. 2020;320(3):C355-C364. doi:10.1152/ajpcell.00403.2020

13. Follis AV, Galea CA, Kriwacki RW. Intrinsic protein flexibility in regulation of cell proliferation: Advantages for signaling and opportunities for novel therapeutics. Adv Exp Med Biol. 2012;725:27-49. doi:10.1007/978-1-4614-0659-4_3

14. Livak KJ, Schmittgen TD. Analysis of relative gene expression data using real-time quantitative PCR and the $2^{-\Delta \Delta c t}$ method. Methods. 2001;25(4):402-408. doi:10.1006/meth.2001.1262

15. Zhou ZH, Shi L, Lang MJ, Chen ZL, Wang YL, He S. Effect of fibroblast growth factor 1 on the proliferating cell nuclear antigen expression in submandibular gland of diabetic mice [in Chinese]. Zhonghua Kou Qiang Yi Xue Za Zhi. 2017;52(5):294-299. doi:10.3760/ cma.j.issn.1002-0098.2017.05.007

16. Strojan $P$, Hutcheson $K A$, Eisbruch A, et al. Treatment of late sequelae after radiotherapy for head and neck cancer. Cancer Treat Rev. 2017; 59:79-92. doi:10.1016/j.ctrv.2017.07.003

17. de Almeida PDV, Gregio AM, Machado MA, de Lima AA, Azevedo LR. Saliva composition and functions: A comprehensive review.J Contemp Dent Pract. 2008;9(3):72-80. PMID:18335122

18. Jensen SB, Vissink A, Limesand KH, Reyland ME. Salivary gland hypofunction and xerostomia in head and neck radiation patients. J Natl Cancer Inst Monogr. 2019;2019(53):Igz016. doi:10.1093/jnci monographs/lgz016

19. Almstahl A, Skoogh Andersson J, Alstad T, Fagerberg-Mohlin B, Finizia C. Explorative study on quality of life in relation to salivary secretion rate in head and neck cancer patients treated with radiotherapy up to 2 years post treatment. Int J Dent Hyg. 2019;17(1):46-54. doi:10.1111/ idh. 12363

20. Uchiyama Y, Kreiborg S, Murakami S, Tsujimoto T, Sumida I. Changes in the submandibular gland in patients with head and neck cancer after resection therapy: A preliminary study. Anticancer Res. 2017; 37(6):3239-3242. doi:10.21873/anticanres.11686

21. Hayashi T, Koyama N, Azuma Y, Kashimata M. Mesenchymal miR-21 regulates branching morphogenesis in murine submandibular gland in vitro. Dev Biol. 2011;352(2):299-307. doi:10.1016/j.ydbio.2011.01.030

22. Hayashi T, Koyama N, Gresik EW, Kashimata M. Detection of EGFdependent microRNAs of the fetal mouse submandibular gland at embryonic day 13. J Med Invest. 2009;56(Suppl):250-252. doi:10.2152/ jmi.56.250

23. Luo Q, Zhu J, Zhang Q, Xie J, Yi C, Li T. MicroRNA-486-5p promotes acute lung injury via inducing inflammation and apoptosis by targeting OTUD7B. Inflammation. 2020;43(3):975-984. doi:10.1007/s10753020-01183-3

24. Fan J, Shi S, Qiu Y, Zhang Z, Yu L. MicroRNA-486-5p down-regulation protects cardiomyocytes against hypoxia-induced cell injury by targeting IGF-1. Int J Clin Exp Pathol. 2019;12(7):2544-2551. PMID: 31934081

25. Ma R, Wang C, Wang J, Wang D, Xu J. miRNA-mRNA interaction network in non-small cell lung cancer. Interdiscip Sci. 2016;8(3):209-219. doi:10.1007/s12539-015-0117-8 